COMECHINGONIA. Revista de Arqueología. Vol. 23, n² 2. Segundo semestre de 2019. ISSN: 0326-7911

\title{
ANIMALES Y RITUALIDAD EN EL MUNDO INKA. UN CASO DE ESTUDIO EN EL SITIO ARQUEOLÓGICO EL SHINCAL DE QUIMIVIL (LONDRES, CATAMARCA).
}

\section{ANIMALS AND RITUALITY IN THE INKA WORLD. THE ARCHEOLOGICAL SITE EL SHINCAL DE QUIMIVIL (LONDRES, CATAMARCA) CASE STUDY.}

\author{
Mariana V. Valderrama ${ }^{1}$ y Marco A. Giovannetti² \\ ${ }^{1}$ División Arqueología, Facultad de Ciencias Naturales y Museo, Universidad Nacional de La Plata. \\ Paseo del Bosque s/n, La Plata. E-mail: mvalderrama27@gmail.com \\ ${ }^{2}$ CONICET - División Arqueología, Facultad de Ciencias Naturales y Museo, Universidad Nacional \\ de La Plata. Museo de La Plata, Paseo del bosque s/nº (1900), La Plata. \\ E-mail: mgiovannetti@conicet.gov.ar
}

Presentado: 07/05/2019 - Aceptado: 20/10/2019

\section{Resumen}

El objetivo del presente trabajo es presentar los resultados del análisis del conjunto arqueofaunístico recuperado del Recinto 62 del Complejo 17 del sitio El Shincal de Quimivil (período inka con breve ocupación durante el hispano-indígena), a través de una perspectiva que destaca las posibles relaciones que se forjaron entre personas humanas y no humanas (Hallowell 1960). Este análisis pretende discutir dichos resultados relacionándolos con prácticas de uso y consumo en un contexto ritual. Las múltiples investigaciones realizadas en el sitio, permiten interpretarlo como un centro de importancia política y administrativa en la estructura del Tawantinsuyu (Raffino 2004), donde se celebraban importantes fiestas y ceremonias del calendario oficial. En las mismas se compartían abundantes cantidades de comidas y bebidas entre diversas comunidades (Giovannetti 2009, Giovannetti et al. 2012). Aqui, los restos faunísticos juegan un importante papel para la interpretación de las prácticas de comensalismo (Bray 2012). Los resultados zooarqueológicos obtenidos contribuyen a la discusión acerca del uso y consumo de animales en el pasado inkaico, específicamente en aquellos eventos que exceden la cotidianeidad. Su articulación con el análisis de otros elementos (cerámica, rasgos arquitectónicos y restos arqueobotánicos), junto a su disposición espacial, ha permitido destacar el carácter ritual del contexto.

Palabras claves: Zooarqueología, Ritualidad, Inka, Noroeste argentino, Comensalismo.

\section{Abstract}

This research work aims to describe the results of the archeological collection recovered from Precinct 62 of Complex 17, at the El Shincal de Quimivil site (Inka period with brief occupation during the Hispanic-indigenous), through a perspective that highlights the possible interactions 
between human and non-human persons (Hallowell 1960). The purpose of the analysis is to compare its results with ritualistic use and consumption practices. A variety of research at the site allows for its interpretation as a political and administrative center of relevance within the structure of Tawantinsuyu (Raffino 2004), where significant ceremonies and celebrations of the official calendar were held. During such, abundant/plentiful amounts of food and beverages were shared amongst diverse communities (Giovannetti 2009, Giovannetti et al. 2012). There, faunistic remains play a pivotal role for the interpretation of commensalism practices (Bray 2012). The zooarcheological results obtained contribute to the debate concerning the use and consume of animals in Inkaic past, specifically during those events that exceed every-day life. Its articulation with the analysis of other elements (pottery, architectonics and archeobotanical remains), as well as their spatial disposition, has allowed for the highlighting/recognition of the ritualistic character of the context in which they occurred.

Key words: Zooarchaeology - Rituality - Inka -Argentine Northwest-Commensalism.

\section{Introducción}

A fines del siglo $\mathrm{XV}$, el mundo inka ocupaba un extenso territorio denominado Tawantinsuyu (Raffino 1999). En el idioma quechua, Tawantinsuyu se traduce como "lugar de las cuatro regiones", las cuales se encontraban articuladas por un extenso camino (Qhapaq Ñan) que recorría de norte a sur la costa del Pacífico, los Andes y las selvas amazónicas. Pero el concepto va más allá de la idea de espacio conquistado, implica según Rostworowski (1999) el deseo indígena hacia la unidad. A lo largo del Tawantinsuyu, la mayor extensión de territorio al sur de Perú se denominó Qollasuyu (Murra 1999; Rostworowski 1999), abarcando desde el Lago Titicaca hacia el sur, y ocupando las actuales regiones del occidente de Bolivia, mitad boreal de Chile y el Noroeste argentino (Raffino 1981). La expansión de los inkas en esta región, implicó la reconfiguración del paisaje regional, resignificando la espacialidad previa, como así también, introduciendo cambios tecnológicos en las comunidades locales, produciendo una intensificación a nivel artesanal, minero metalúrgico y agro pastoril (D’Altroy 2002). También se produjo un intenso entramado de vínculos novedosos relativos a la dimensión de la cosmovisión, dado que no existió una imposición dura de una ideología estatal sino más bien una incorporación de las lógicas y sentidos de las comunidades nativas materializados muchas veces en la asimilación de las wakas locales (Giovannetti y Lynch 2019). Todos estos cambios no fueron homogéneos a lo largo de la región ni fueron asimilados pasivamente por las poblaciones locales. Pero sin duda, siguiendo a Acuto (1999) la percepción sobre el espacio debió haber jugado un rol fundamental para el desarrollo de determinadas prácticas y el establecimiento de relaciones sociales que los inkas deseaban introducir, configurándose, de esta forma, como un dispositivo particular de dominación. 


\section{El sitio arqueológico y su contexto}

El Shincal de Quimivil es un sitio con ocupación inkaica, emplazado al noroeste del actual pueblo de Londres, provincia de Catamarca, Argentina. Se ubica sobre el extremo noroeste de un amplio cono aluvial, delimitado por el curso de los ríos Quimivil y Hondo (Giovannetti 2015). Pertenece a la provincia fitogeográfica del Monte de la región Neotropical (Cabrera y Willink 1973), caracterizada por grandes bosques de Prosopis sp., y otras especies arbóreas como tala (Celtis tala), chañar (Geoffroea decorticans) y shinki (Mimosa farinosa), entre otras. Según Cabrera y Yepes (1947), la zoogeografía de la zona se caracteriza por mamíferos, entre ellos cérvidos como la taruca (Hippocamelus antisensis) y la corzuela (Mazama gouazoubira), camélidos (silvestres: Lama guanicoe, Vicugna vicugna; domésticos: Lama glama), armadillos (Chaetophractus vellerosus y Chaetophractus villosus), félidos (Puma concolor, Leopardus pajeros, Leopardus geoffroyi), cánidos (Lycalopex culpaeus, Lycalopex griseus) y roedores (Lagidium viscacia, Lagostomus maximus, Chinchilla sp., Dolichotis patagonum, Galea musteloides, Ctenomys sp., entre otros). Entre los reptiles podemos encontrar las iguanas (Tupinambis sp.), geckónidos (Homonota sp. y Gymnodactylus $s p$.$) , lagartijas (Leyosaurus sp., Liolaemus sp. y Tripidurus sp.), serpientes (Constrictor$ constrictor, Bothrops sp.) y tortugas (Geochelone sp.). En cuanto a las aves, las que predominan son el ñandú petiso (Rhea pennata), el lechuzón (Rhinoptynx clamator mogenseni), tinamúes (Nothoprocta cinerascens, Nothoprocta ornata), entre otras.

El sitio ha sido intensamente abordado desde la arqueología y es considerado como uno de los enclaves inkaicos más importantes del Qollasuyu, en términos de magnitud y calidad de la arquitectura conspicua. A los más de setenta recintos se le suman espacios abiertos y muros delimitadores, además de ochenta almacenes circulares del tipo qolqa. Todo este conjunto fue construido exclusivamente con rocas canteadas, una característica prácticamente única en el NOA. El núcleo del sitio se constituye a partir de una gran plataforma ushnu ubicada subcentralmente a la gran plaza hawkaipata. Es posible identificar edificios de carácter político administrativo como el caso del conjunto de kallankas. Pero son más abundantes y notorias las estructuras que se vincularían a la dimensión del ceremonialismo (Figura 1). Cuatro cerros cercanos de una altura relativamente baja fueron incorporados en un esquema que prioriza los ejes cardinales (Giovannetti 2018). Dos de estos cerros (este y oeste) se ubican dentro de los límites actuales a 200 metros de la plaza. Otros dos (norte y sur) están por fuera, pero aun así, se conectan específicamente con el ushnu a través de direcciones precisas con estructuras rocosas sacralizadas. Por otro lado, todos fueron transformados en gran parte con edificios, muros, escaleras y rocas talladas.

En el año 2011 se efectuaron los trabajos de campo en el Recinto 62 del Complejo 17, los cuales dejaron al descubierto algunas sorpresas, sobre todo en los últimos niveles estratigráficos. Al mismo tiempo, se corroboraron algunas hipótesis de partida. Lo 
primero se relaciona al hallazgo de estructuras peculiares difíciles de encontrar en otros espacios construidos del sitio. Es el caso de una corta pasarela de piedra que conecta el ingreso del recinto con probables pozos para depositar ofrendas. Pero la morfología particular de este espacio, mapeada y analizada previamente a la excavación, nos daba indicios de que estábamos en presencia de un espacio de culto. Los detalles arquitectónicos internos no fueron las únicas de las sorpresas. La identificación de un espacio de cocción y consumo de alimentos, generalmente atribuidos a espacios domésticos, permitió replantearnos las categorizaciones establecidas en la arqueología tradicional.

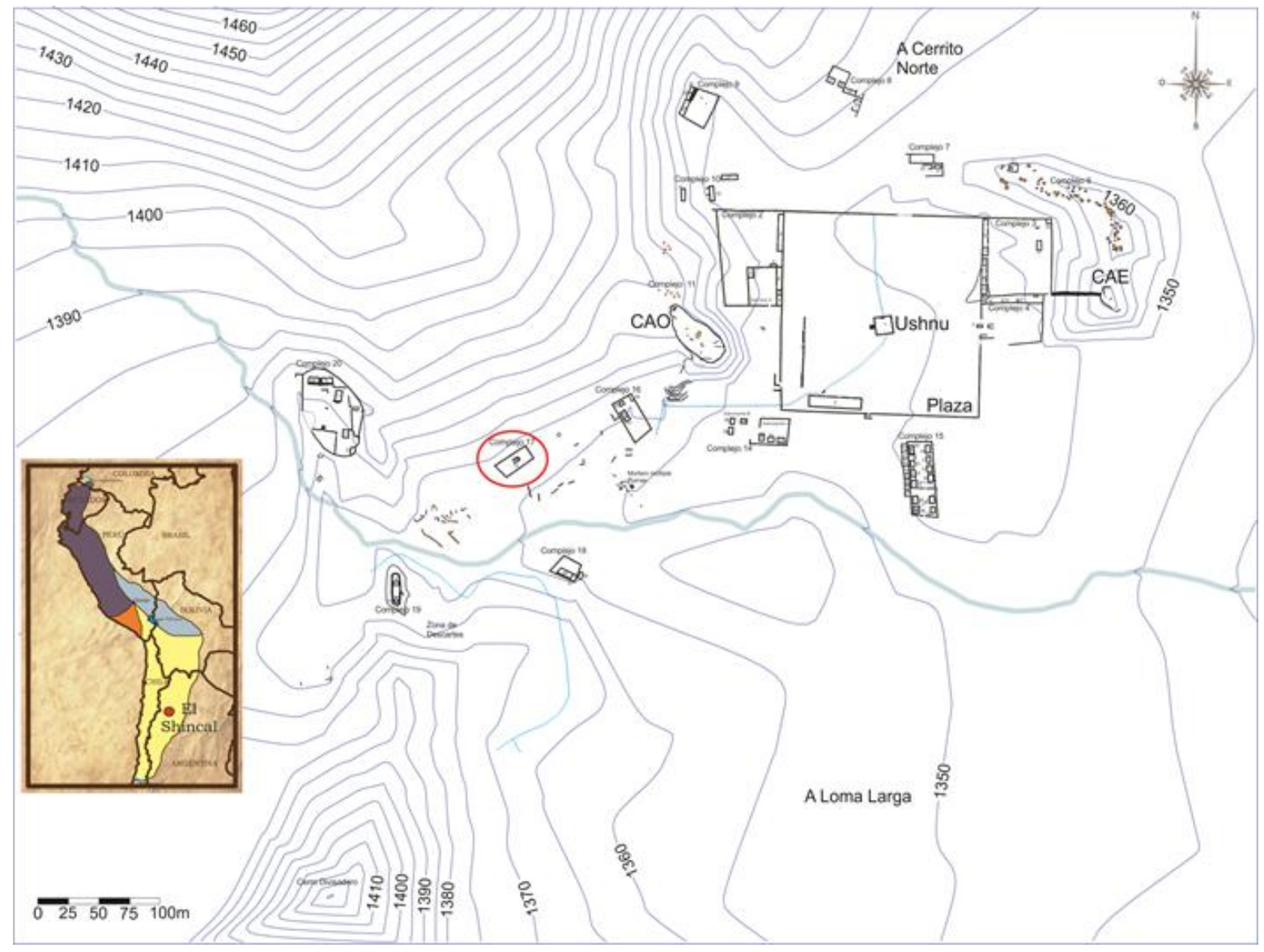

Figura 1: Mapa topográfico del sitio El Shincal de Quimivil. Detalle del Complejo 17 - Recinto 62. A la izquierda se muestra la ubicación del sitio en relación a las cuatro divisiones del Tawantinsuyu.

\section{Aspectos conceptuales}

Sin bien en los últimos años los trabajos zooarqueológicos han tratado múltiples dimensiones de las relaciones sociales, entre ellas la ritualidad (Politis et al. 2005; Urquiza y Babot 2018), es recurrente encontrarse con trabajos que se han enfocado únicamente en el análisis de la fauna desde una perspectiva utilitaria y de subsistencia. Dichos enfoques 
pierden de vista a los animales como sujetos participantes y constituyentes de la sociedad, recayendo en una perspectiva dicotómica de los contextos de hallazgo. En contraste a ello, el presente trabajo toma como concepto fundamental la idea de comensalidad, la cual implica participar o compartir comida y bebida en un mismo espacio, cuyo fin o consecuencia es la construcción de relaciones específicas de sociabilidad (Bray 2012). La comida, en su preparación y consumo, involucra personas. La idea de persona responde a identidades, facultades y disposiciones que la agencia toma en la interacción con otras personas, sean humanas o no (Hallowell 1960). Entendemos por personas no humanas a los animales (para nuestro interés particular) y otras entidades que actúan como agentes sensitivos e independientes, los cuales se constituyen socialmente (Hill 2013). Lejos de caer en recurrentes clasificaciones acerca de espacios domésticos versus rituales, la idea de comensalidad permite explorar qué cosas se consumían, de qué forma se hacía, en dónde y con quién se compartía. Así, se pone el foco en los tipos de relaciones sociales, los contextos y la simbología inherente. La subsistencia se convierte por ende en uno más -y no ya en el más importante- de los aspectos que deben tenerse en cuenta al momento de interpretar.

La comensalidad ritual, en términos de Bray (2012), refleja la construcción de relaciones sociales por fuera del ámbito familiar y sería el medio para explorar el universo social y la ontología indígena de los grupos humanos. Particularmente en el mundo inka, esto se encuentra íntimamente relacionado con las prácticas festivas, regidas por las fechas establecidas en el calendario estatal (Ziolkowski 2015). En las mismas, el comer y el beber no se restringe a las personas humanas, sino que también, se comparte con personas no humanas. La práctica en la que se materializa dicha interacción es la ofrenda (Sillar 2009). En este acto, los seres y personajes sagrados se configuran como comensales al compartir ofrendas culinarias, las cuales expresan uno de los otros conceptos centrales del mundo andino: reciprocidad (Fernández Juárez 1994; Aguilera 2008).

Es por lo mencionado, que el presente trabajo pretende desarrollar con detalle el fenómeno del comensalismo dentro de un recinto destinado principalmente a prácticas de culto y ceremonialismo. El foco estará puesto en el análisis zooarqueológico de los restos faunístico recuperados en el Recinto 62, como parte del consumo y el uso de los mismos en actividades que fueran parte de la parafernalia ceremonial.

\section{El Recinto ceremonial - Recinto 62 del Complejo 17}

Durante las prospecciones realizadas en el sitio, una estructura emplazada en el sector oriental se destacó por su morfología y disposición, tanto del recinto analizado como del espacio exterior circundante (Figura 2). Se trata del que denominamos Complejo 17, según la nomenclatura establecida por nuestro equipo de investigación. Si bien en la arquitectura inka una de las morfologías más recurrentes busca reproducir formas rectangulares, este espacio escapa de tal regularidad. La dirección de los muros laterales del Complejo 17 conforma un trapecio irregular. Existen casos en edificios importantes en el Cusco, 
específicamente en el Qorikancha y en Saqsayhuaman que representan esta forma en planta (Ríos Mencias 2012). Descontando las tan difundidas formas de puertas y hornacinas muy significativas desde lo sagrado, los recintos que tomamos como ejemplos eran de alto valor ceremonial. En nuestro caso es el perímetro externo el que presenta esta morfología, mientras que el recinto interno es rectangular.

Otro aspecto que rompe con el ordenamiento simétrico fue la relación de la orientación entre el recinto exterior y el interior. Por poner un ejemplo, los dos muros paralelos del exterior se desvían unos $11^{\circ}$ respecto del recinto interior. En definitiva existe un notable desfasaje entre la orientación del recinto interior y cualquiera de los muros exteriores. Al no existir explicación funcional o instrumental que otorgue sentido a este desacople podemos reconocer solamente la búsqueda simbólica de orientar cada parte hacia objetivos exteriores que aún no hemos identificado. Ambas entradas, tanto la del complejo como la del recinto, se emplazan hacia el SO. Difieren entre sí en cuanto a la ubicación en el muro, mientras que el ingreso del complejo se encuentra en uno de los extremos, el del recinto se sitúa sobre el sector central (Figura 2).

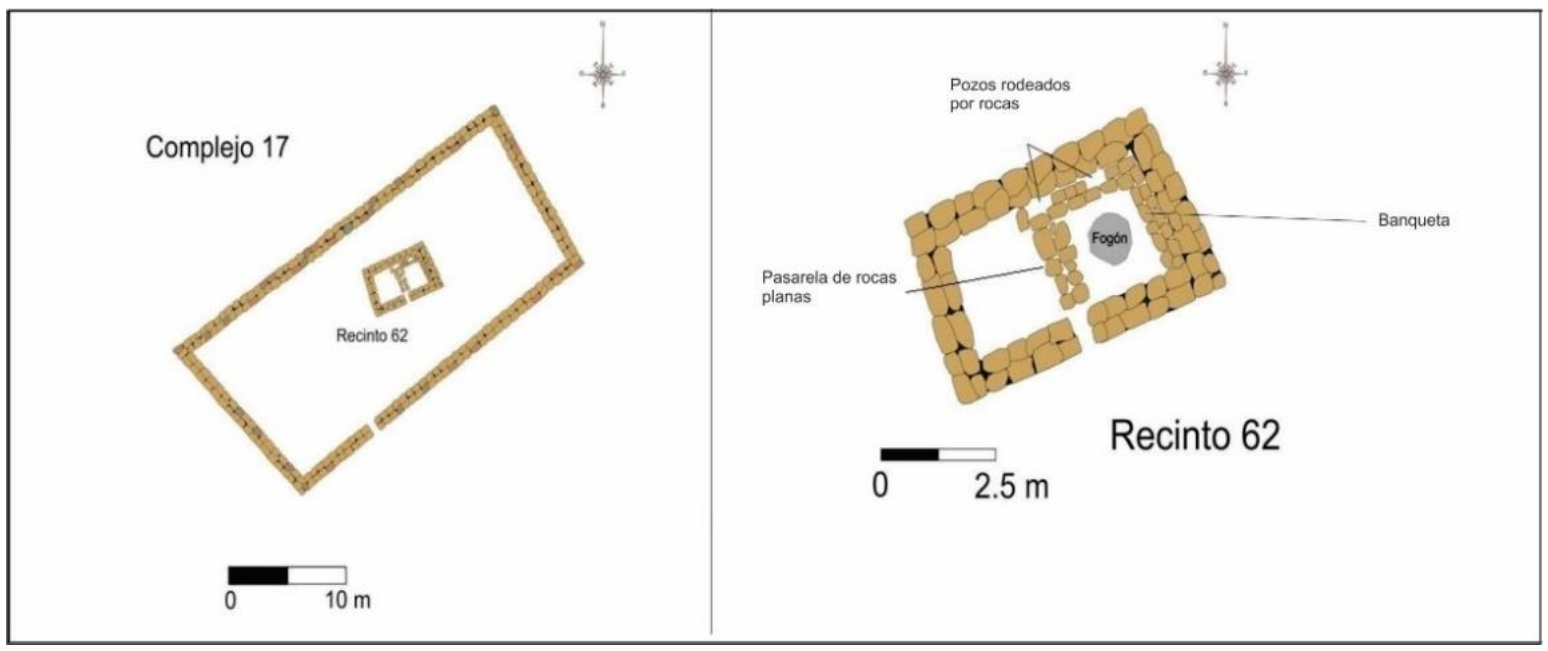

Figura 2. Esquema del Complejo 17 y detalle del Recinto 62.

Al igual que el Complejo 17, el Recinto 62 no estuvo techado. El cálculo de altura y análisis de derrumbe de los muros, a partir del piso ocupacional hallado durante la excavación, arrojó una estimación máxima de 1,3 m, una medida baja para los parámetros regulares de la arquitectura inka. El interior de este recinto mide $15 \mathrm{~m}^{2}$ (5 x $3 \mathrm{~m}$ ) y la entrada se ubica en el medio de una posición simétrica. Su jamba está levemente inclinada rememorando la forma trapezoidal. El piso de ocupación, detectado entre los 0,80 y 0,90 m de profundidad desde la actual superficie, presentaba un panorama heterogéneo. Por una parte hallamos una pasarela revestida en piedra planas que corría desde la entrada hasta la pared opuesta. En ese espacio se detectaron los restos de un sector demarcado con rocas, pero lo más destacable fueron dos pozos revestidos también en roca (Figuras 3 A y B). Los 
mismos fueron interpretados como espacios cuidadosamente preparados para verter ofrendas líquidas, es decir libaderos (Pino Matos 2010). Sobre la otra pared perpendicular contigua fueron construidas banquetas pegadas a la pared, una característica arquitectónica inka que se interpreta como lugar preparado para que los ocupantes de un espacio tuvieran su lugar de asiento (Figura 4A). Restos pequeños de carbón aparecieron a lo largo de toda la excavación. A una profundidad de 0,73 m sobre el lado derecho (tomando como referencia la entrada) se registraron evidencias de un gran fogón, cuyo espacio central se encontraba delimitado con algunas rocas. El contorno externo presentaba una forma subcircular con diámetro cercano a $1 \mathrm{~m}$ y las rocas no llegaban a cubrir ordenadamente todo el perímetro (Figura 4B).
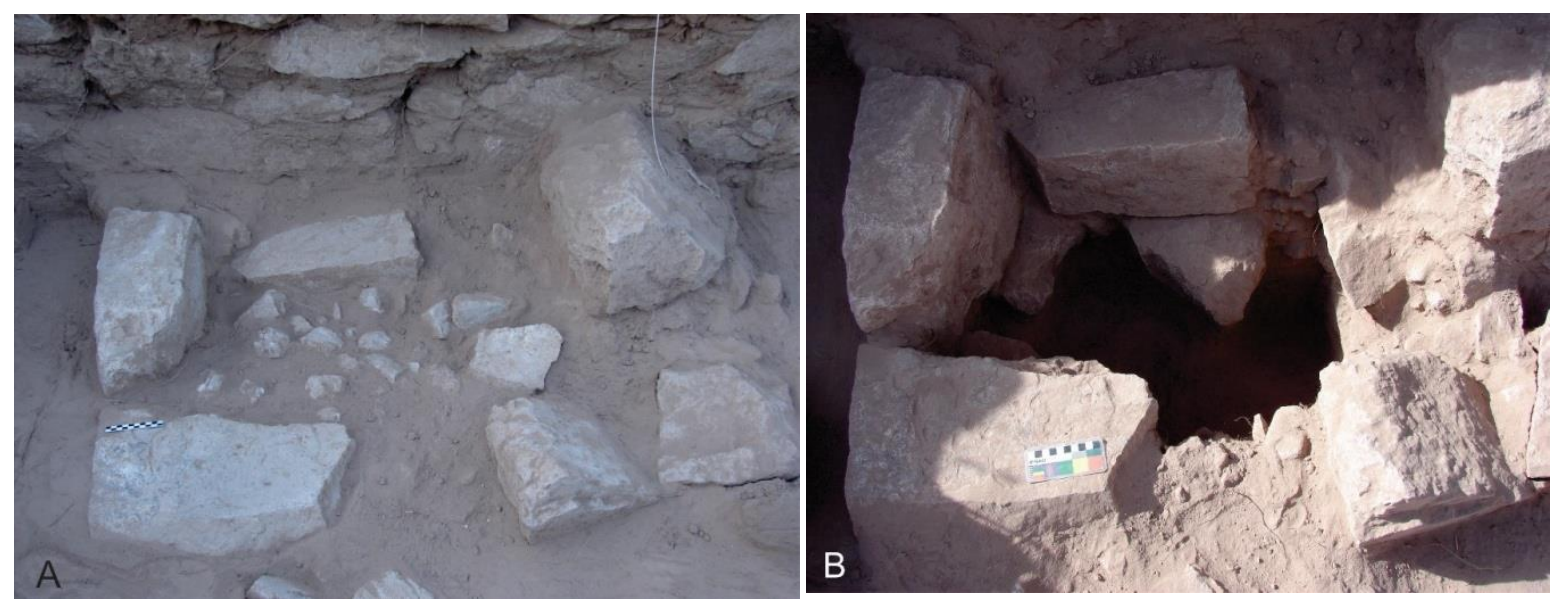

Figura 3. Pozos de libación. A) Relleno con pequeños rodados. B) Detalle de profundidad.

Abundantes fragmentos cerámicos fueron recuperados en todo el recinto. Sobre un total de 247 tiestos identificados, alrededor de un 40\% correspondían a fragmentos de cerámica tosco-utilitaria, principalmente de ollas. Algunos de estos ejemplares contenían evidencia de haber sido expuestos al fuego. Por otra parte, un 26\% de la muestra cerámica se identificó como inka provincial, destacándose restos de platos y aríbalos. Luego se observa una dispersión entre varios estilos cerámicos de representación minoritaria. Se destacan entre estos fragmentos de estilos Belén, Santamaría, Famabalasto tanto negro como negro/rojo, Sanagasta, Yocavil y unos fragmentos transcordilleranos identificados como Diaguita Inka. En la figura 5 se expone la distribución espacial de los hallazgos donde es posible observar la ausencia de un patrón claro. Tanto el material cerámico como el óseo y el lítico se distribuyen a lo largo de todo el recinto. 

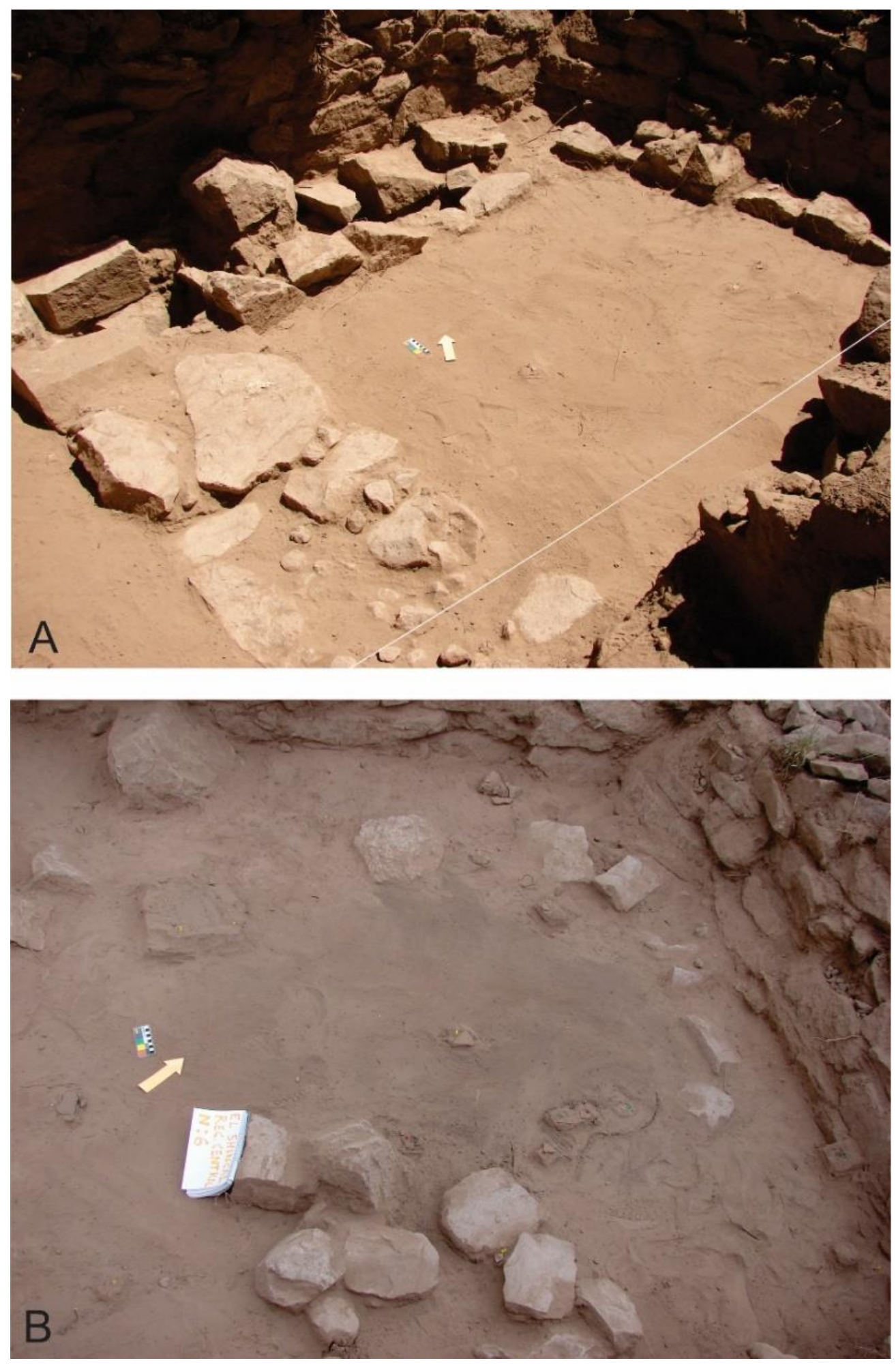

Figura 4. A) Interior del recinto 62. Se observa la pasarela de rocas planas conectada con los dos orificios de la pared opuesta. B) Detalle de fogón central rodeado de rocas. 


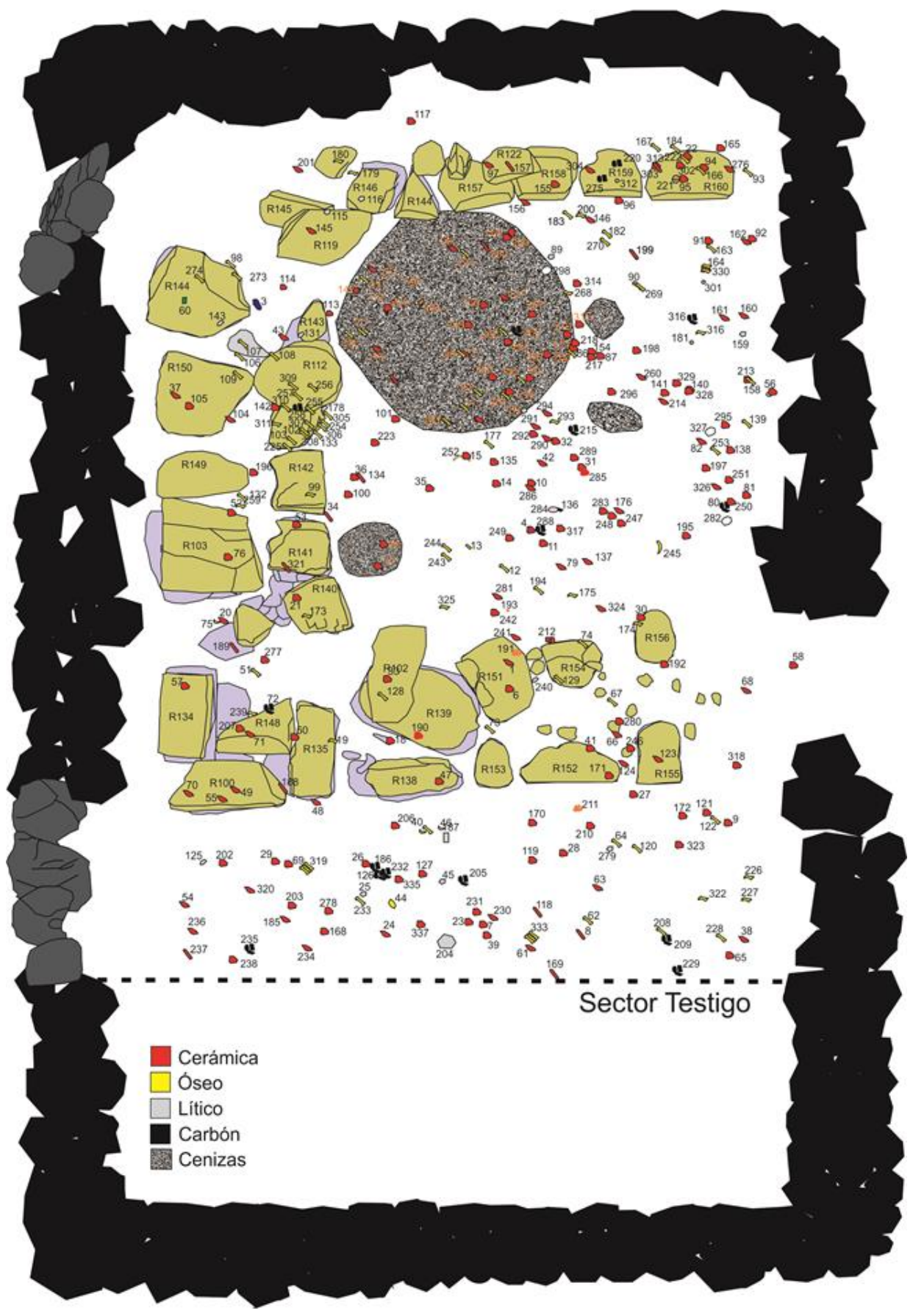

Figura 5. Planta de excavación del Recinto 62 con la totalidad de hallazgos.

A partir de los 0,45 $\mathrm{m}$ de profundidad se observó un evento discreto relacionado con una capa de rodados de tamaño relativamente regular (entre 4 a $10 \mathrm{~cm}$ ) que cubría la mayor parte de la superficie del recinto. Esta distribución de rodados continuó hasta la aparición del piso de ocupación, aproximadamente a los 0,80 m de profundidad (Figura 6). Según nuestras interpretaciones esta acumulación resulta ser producto de una búsqueda intencional de cubrir parte del recinto con tierra y piedras. Podría decirse que funcionaría 
como un evento de clausura una vez que este recinto fue abandonado. Debido al empleo de rodados de tamaño regular, similares a los que componen los libaderos (e.g. Ushnu, Complejo 20, Loma Larga, Recinto 62), creemos que este suceso responde a un acto de abandono ritual. Farrington (2014) al excavar el sitio Tambokancha en Zurite, cercano al Cusco, encuentra que la mayoría de los recintos de carácter ceremonial también fueron bloqueados en sus entradas y pasillos con restos de alfarería, rocas y tierra. Esto ocurrió como parte del abandono del lugar a la llegada de los españoles. Pero ese abandono se produjo a través de actos ceremoniales de clausura. Creemos que el evento observado en el Recinto 62 fue parte de actos de similar porte.

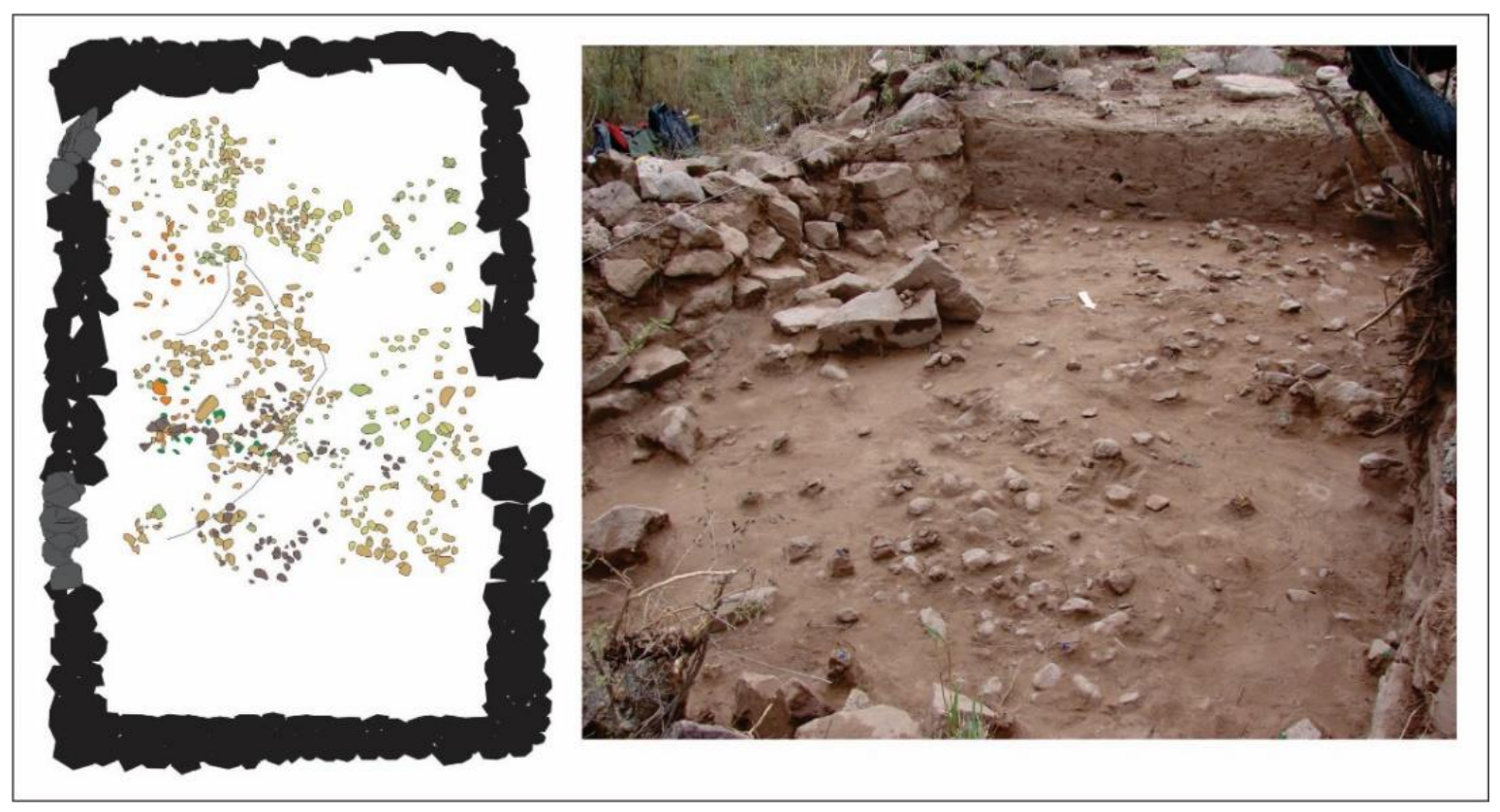

Figura 6. Planta arqueológica con detalle de evento de clausura.

\section{Metodología de análisis}

Los restos arqueofaunísticos analizados fueron recuperados durante el año 2011. En esa campaña, se realizaron las excavaciones y el correspondiente levantamiento topográfico del recinto, lo cual arrojó abundantes restos arqueológicos y destacables rasgos arquitectónicos. Los materiales óseos provienen de los distintos niveles artificiales y unidades estratigráficas, donde fue posible discriminar -de abajo hacia arriba- el piso ocupacional, un posterior relleno de abandono y finalmente un derrumbe de paredes.

La metodología utilizada para el análisis zooarqueológico, se basó en criterios de uso cotidiano en la bibliografía (Lyman 1994; Mengoni Goñalons 1988, 2010). El trabajo que aquí presentamos se cumplió en dos etapas. La primera involucró la determinación anatómica y taxonómica de los especímenes, y la obtención de los distintos estimadores 
(NISP, \%NISP y MNI), con el objetivo de definir y evaluar la composición del conjunto zooarqueológico. Las determinaciones se realizaron siguiendo los estándares de las ciencias biológicas (Salemme et al. 1989), en conjunto con el método de zonas diagnósticas propuesto por Mengoni Goñalons (1999). Para ello, se emplearon las muestras comparativas provenientes de las colecciones de la División Zoología de vertebrados de la Facultad de Ciencias Naturales y Museo (UNLP) y guías osteológicas, como por ejemplo para la familia Camelidae (Pacheco Torres et al. 1979). Para el caso de los mamíferos, se establecieron categorías inclusivas según rangos de peso (Mengoni Goñalons 1999): Mamífero grande $(>50 \mathrm{Kg})$ coincidente con representantes sudamericanos de la familia Camelidae y la familia Cervidae, como el caso de Hippocamelus sp.; Mamífero mediano (entre 50 y $15 \mathrm{Kg}$ ) el cual incluye taxones como Mazama sp. y Puma concolor; Mamífero pequeño $(<15 \mathrm{Kg})$ como es el caso de los dasipódidos y micromamíferos ( $<1 \mathrm{~kg})$ Ctenomys $s p$., roedores sigmodontinos.

Para el caso de los camélidos se utilizaron criterios para establecer la estructura de edad relativa de los individuos, teniendo en cuenta la fusión epífisiaria y diafisiaria de los huesos largos, erupción y desgaste de la dentición. Aquí se utilizan las categorías establecidas por Yacobaccio y Madero (1992) para huesos fusionados de individuos adultos y para huesos no fusionados de individuos juveniles.

La segunda etapa implicó el análisis de las modificaciones naturales y culturales presentes en las superficies óseas de los especímenes, que nos permitieran evaluar el grado de preservación del conjunto y los agentes involucrados en su formación. El interés particular depositado en el análisis de aquellas modificaciones estrictamente humanas (marcas de procesamiento, fragmentación, alteración térmica) radica en que a partir de ellas se pueden explorar aspectos vinculados al uso y forma de preparación que los alimentos pudieron tener en el sitio. Entre las modificaciones naturales se evaluaron los estadios de meteorización en los especímenes óseos de aquellos taxones que integran las categorías de peso equivalentes a mamíferos medianos y grandes. (Behrensmeyer 1978), marcas producto de la actividad de carnívoros (Binford 1981; Mengoni Goñalons 1999), raíces, pisoteo, y roedores (Lyman 1994). Por otro lado, entre las marcas de procesamiento se reconocieron huellas de corte, puntos de impacto y fracturas intencionales (Mengoni Goñalons 2010). Asimismo, se determinó la presencia de especímenes óseos con indicios de alteración térmica a partir de los criterios de color y textura (Shipman et al 1984; Lyman 1994; Mengoni Goñalons 1999; Fernández Jalvo y Andrews 2016). Las categorías que aquí empleamos son: huesos con coloración marrón a negra (bajo grado de exposición); con coloración negra sobre toda la superficie, aspecto craquelado y vítreo (carbonizados); coloración grisácea azulada a blanca, con mayor agrietamiento (huesos calcinados). Aunque dicho criterio ha sido discutido, continúa manteniendo su valor diagnóstico. Si bien no es posible establecer una temperatura exacta a la que fue sometido el resto óseos, arroja información acerca de las etapas de exposición (Mengoni Goñalons 1999). 


\section{Resultados}

El conjunto arqueofaunístico procedente del Recinto 62 se encuentra integrado por un total de 1161 especímenes, de los cuales 693 (60\%) pudieron ser identificados a algún nivel taxonómico o anatómico (se incluyen las cáscaras de huevo de Rhea sp.). Entre éstos fueron registrados vertebrados e invertebrados, siendo los primeros los más abundantes, alcanzado un $89 \%$ del NISP. En la tabla 1 se resumen las frecuencias estimadas de NISP y \%NISP, presentándose con mayor representación los roedores con un 30\%. Dentro de este grupo se identificó Ctenomys sp. y a nivel familia, Caviidae. En segundo lugar de importancia se encuentran los camélidos, con valores cercanos al 5\% del NISP. Debe destacarse además, aunque en baja frecuencia, la presencia de las especies Chaetophractus vellerosus e Hippocamelus sp. El primero de éstos se encuentra representado mayormente por placas óseas móviles de la armadura, mientras que el segundo, está representado únicamente por una asta. Asimismo, la frecuencia que se observa para Rheidae está dada por una única falange y numerosos fragmentos de cáscaras de huevo $(n=81)$.

\begin{tabular}{|l|l|l|l|}
\hline Recinto 62 - Complejo 17 & NISP & \% NISP & MNI \\
\hline Mollusca indet. & 11 & 1,80 & - \\
\hline Gastropoda indet. & 67 & 10,95 & - \\
\hline Anura indet. & 47 & 7,68 & 2 \\
\hline Reptilia indet. & 2 & 0,33 & 1 \\
\hline Ave indet. & 4 & 0,65 & - \\
\hline Rheidae indet. & 1 & 0,16 & 1 \\
\hline Mammalia indet. & 15 & 2,45 & - \\
\hline Micromamífero indet. & 126 & 20,59 & - \\
\hline Marsupialia indet. & 1 & 0,16 & 1 \\
\hline Rodentia indet. & 74 & 12,09 & - \\
\hline Ctenomys sp. & 146 & 23,86 & 4 \\
\hline Caviidae indet. & 3 & 0,49 & 1 \\
\hline Sigmodontinae indet. & 1 & 0,16 & 1 \\
\hline Graomys griseoflavus & 2 & 0,33 & 2 \\
\hline Mammalia indet. pequeño & 9 & 1,47 & - \\
\hline Chaetophractus vellerosus & $3(16)$ & 3,10 & 1 \\
\hline Mammalia indet. mediano & 4 & 0,65 & - \\
\hline Mammalia indet. grande & 48 & 7,84 & - \\
\hline Camelidae indet. & 31 & 5,07 & 2 \\
\hline Hippocamelus sp. & 1 & 0,16 & 1 \\
\hline TOTAL & 612 & $100 \%$ & \\
\hline
\end{tabular}

Tabla 1: Totales de NISP, \%NISP y MNI del Recinto 62, sin contabilizar los fragmentos de cáscaras de huevo. Se indican entre paréntesis las placas del exoesqueleto. 
En relación al MNI, se observa una mayor frecuencia para invertebrados (Gastropoda indet.), mientras que para vertebrados la frecuencia es menor (Tabla 1). Dentro de estos últimos, al igual que en las frecuencias de NISP, los roedores son los más abundantes, seguidos por la familia Camelidae. El perfil etario de estos ungulados se configura por la presencia de un individuo juvenil y un individuo adulto, teniéndose en cuenta el grado de fusión de epífisis, que permite discriminar para cada individuo.

En cuanto a las modificaciones naturales, un $69 \%$ de la muestra presenta superficie meteorizada concordante con el estadio 1, continuando en orden decreciente los especímenes que se ubican en el estadio 2 , con un porcentaje del $21 \%$ y finalmente un $10 \%$ en el estadio 3. Esta información sugiere un buen estado de preservación del conjunto.

Las marcas de carnívoros, analizadas en categorías de mamíferos medianos a grandes, no fueron observadas en ninguno de los especímenes. No obstante, fueron determinadas marcas de raíces y de roedores en frecuencias muy bajas, menores al $2 \%$ del NISP. Éstas últimas podrían estar relacionadas con la presencia de túneles o galerías que fueron identificadas durante la excavación del complejo, y sumado a su representación, permiten suponer que al menos los Ctenomys sp. registrados en el conjunto, podrían resultar de una incorporación natural al registro.

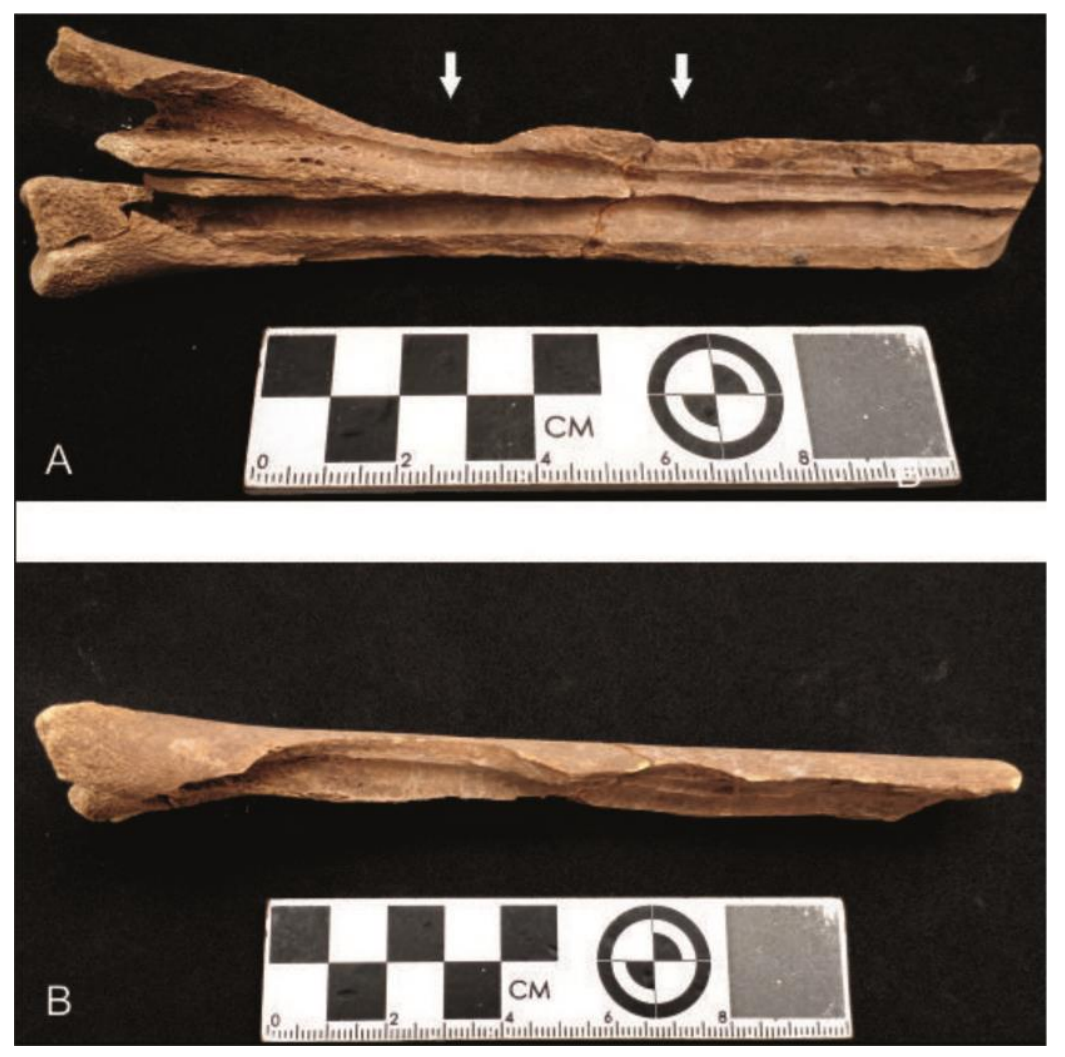

Figura 7. Metapodio de camélido con detalle de marcas de percusión. 
Se reconocieron diversas modificaciones culturales sobre el conjunto, como fracturas intencionales, huellas de corte y puntos de impacto (Mengoni Goñalons 2010). Las mismas se registraron en una frecuencia baja, particularmente en ocho especímenes. Las huellas de corte se reconocieron en tres fragmentos de hueso largo asignados a mamíferos grandes, en un fragmento de hueso largo asignado a mamífero pequeño, en un fragmento de hueso largo asignado a mamífero y en un espécimen indeterminado. El número de las marcas varía de 2 a 6, presentando por lo general, una profundidad media y una orientación transversal. Marcas de percusión se observaron en un metapodio de camélido juvenil (Figura 7). Negativos de lascado y marcas de corte se observaron en un fragmento de hueso largo correspondiente a un mamífero grande.

En cuanto a la termoalteración, pudo ser determinada en un 17\% de los especímenes analizados (en su totalidad vertebrados), entre los cuales fue posible identificar distintas coloraciones que van desde los carbonizados, alcanzando un 36\%, hasta los completamente calcinados (38\%), lo que podría estar reflejando la exposición de los huesos a distintas temperaturas. Aunque el porcentaje más alto de especímenes termoalterados no pudieron ser identificados a nivel taxonómico, aquí también nos interesa destacar las especies en las cuales fue posible observar este efecto debido a que este tipo de modificación sería un indicador del uso humano de dichos animales. Los valores de especímenes con alteración térmica de la familia Camelidae alcanzan un 3\%. Dicha cifra podría ir en ascenso si se tuviera en cuenta el 10\% de termoalteración que se registra entre los mamíferos grande, categoría que podría estar integrada por camélidos no identificados. De todos modos, no se estimó de dicha manera debido a que se observó presencia de Hippocamelus sp. El mismo porcentaje que los camélidos se observó para la categoría de micromamíferos. Seguidamente se ubica Chaetophractus vellerosus en cuya especie se identificó un $2 \%$ de especímenes -placas de la armadura ósea- presentando termoalteración, tanto en su cara interna como externa. Finalmente, se registró un único fragmento de cáscara de huevo perteneciente a la familia Rheidae, con claros signos de alteración térmica.

Entre la muestra arqueofaunística se recuperaron diversos elementos óseos formatizados. Entre ellos puede mencionarse una base de punta ósea, la cual presenta en una de sus caras evidencia de alteración térmica. Debido a su elevado pulido no fue posible identificar el soporte anatómico y taxonómico (Figura 8). Dos cuentas de distintos tamaños, cuyo soporte no pudo ser identificado y cinco preformas de nácar, cuatro fragmentadas y una completa (Figura 9). 

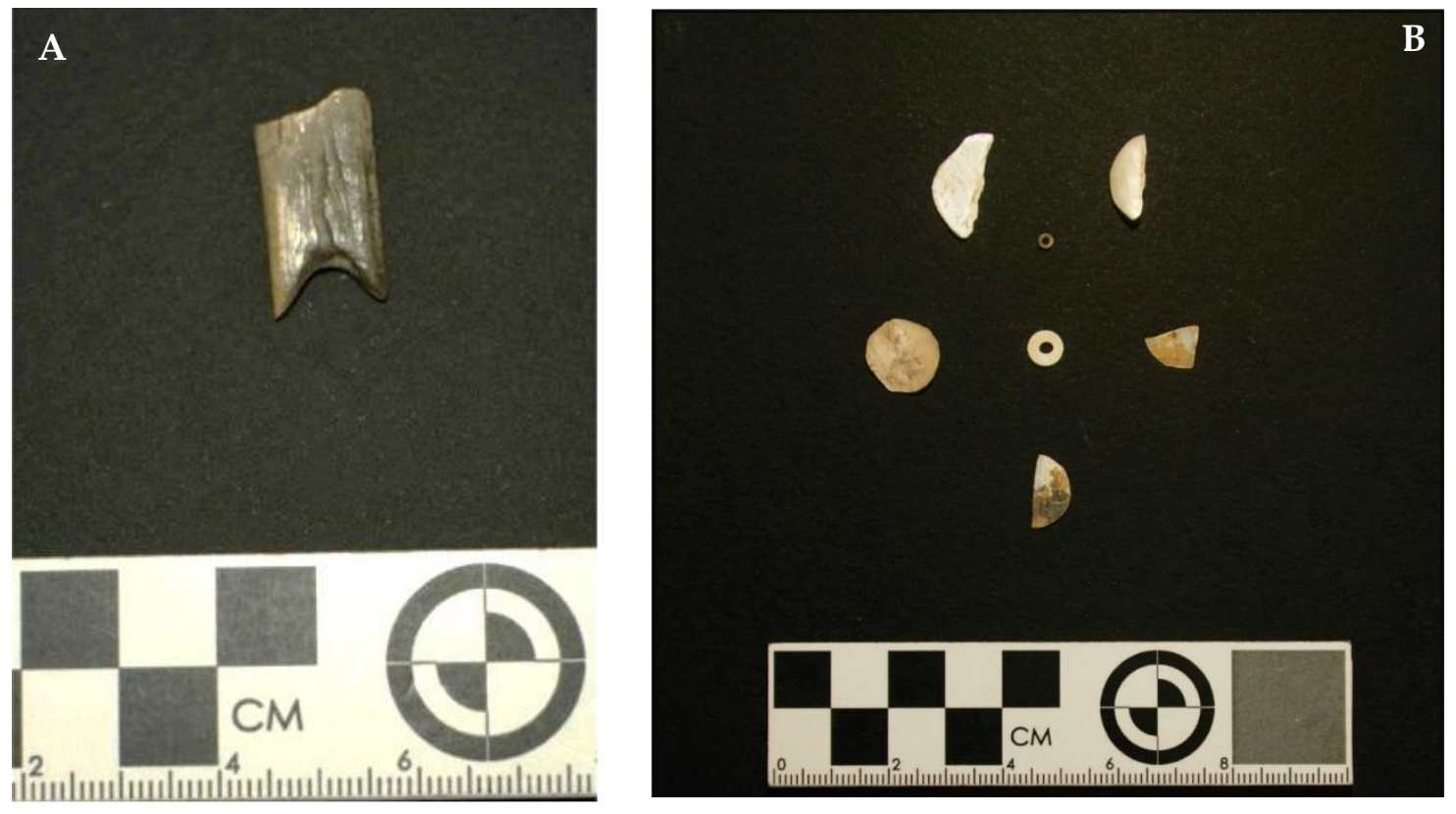

Figura 8. Elementos óseos formatizados: A) base de punta con alteración térmica. B) Cuentas y preformas de nácar.

\section{Discusión}

El presente trabajo representa un avance sobre las investigaciones zooarqueológicas que se vienen desarrollando por nuestro equipo de investigación en el sitio arqueológico El Shincal de Quimivil. Debe destacarse que la información proporcionada por el análisis de restos arqueofaunísticos no sería relevante si se pierde de vista su asociación con otros elementos del registro material, tanto artefactuales como estructurales o arquitectónicos.

Los análisis de meteorización nos muestran que la mayor parte del conjunto presenta superficies bien preservadas, sugiriendo un enterramiento relativamente rápido y una baja probabilidad de que la pérdida ósea haya sido significativa. En cuanto a las otras modificaciones naturales analizadas, no se observaron marcas de carnívoros, y la acción de raíces y roedores no parece haber incidido demasiado en la formación del conjunto, ya que son escasos los materiales que presentan superficies modificadas por ellos.

La muestra arqueofaunística analizada permitió establecer, teniendo en cuenta la multiplicidad de procesos y agentes que intervinieron en su formación, que el principal agente de origen y modificador fue el antrópico. La representación de taxones es variable, entre los cuales la familia Rodentia es la más abundante. La mayoría de los restos de roedores corresponde a Ctenomys $s p$. los cuales hasta el momento carecen de elementos claros que nos permitan asociarlos a un uso antrópico. Las marcas de roedores identificadas, aunque en baja frecuencia, y la presencia de 
túneles o galerías identificadas durante la excavación del recinto, permiten suponer que los individuos de dicha especie y de Graomys griseoflavus, podrían resultar de una incorporación natural al registro. La misma situación se estaría presentando con otros taxones donde no se observó evidencia de manejo antrópico, como en las clases Reptilia, Anura y Gastropoda. Por otra parte, se identificó la presencia de tres especímenes correspondientes a la familia Caviidae, pero no fue posible determinarlos a un nivel más específico. Si bien no se registraron marcas y modificaciones culturales sobre los mismos, las evidencias etnohistórica y etnográfica plantean la importancia de los cuyes domésticos (Cavia porcellus) en la economía, cosmovisión y mundo ritual de los grupos andinos (Chauca Francia de Zaldívar 2007).

Entre los camélidos, cuya representación es cercana al 5\% del conjunto, se observa la presencia de dos individuos, uno juvenil y otro adulto. La representación del individuo juvenil se encuentra dada por elementos del autopodio, con claras marcas de origen antrópico. Del individuo adulto se destacan elementos del cráneo, dentarios completos y fragmentados y algunos elementos del zeugopodio y autopodio. Los elementos dentarios se encuentran termoalterados. Este dato cobra relevancia debido a que en un sector central del recinto, fue identificada la presencia de un fogón, y que daría sustento no solo al uso del fuego dentro de este ámbito sino a la posibilidad de que el quemado de estos materiales sea resultando por ejemplo, de arrojar huesos al fogón, con fines de descarte posteriores al consumo o como parte de las ofrendas.

La presencia de dasipódidos, particularmente la especie Chaetophractus vellerosus, se expresa en una baja frecuencia, representada principalmente por elementos de la armadura ósea. Estos animales suelen registrarse en contextos arqueológicos y vincularse con procesos de perturbación postdepositacional (Rodríguez Loredo 1997-1998), sin embargo la presencia de placas de la armadura ósea termoalteradas nos lleva a plantear la idea de que su presencia en este complejo no haya sido intrusiva y que por lo tanto lo hayan consumido.

Asimismo, los cérvidos, estarían representados únicamente por una asta identificada como de Hippocamelus sp. Debido a su elevado estado de meteorización, no fue posible observar marcas ni algún tipo de pulido. No obstante, teniendo en cuenta esta única representación, podría estar arrojando información acerca de la selección intencional de determinadas partes anatómicas. Existen numerosas investigaciones realizadas en el Noroeste argentino donde se describe la presencia de cornamentas de taruca (Hippocamelus antisensis) en contextos arqueológicos (Angiorama 2005; Martin 2017; Palamarczuk et al. 2006; Tarragó et al. 2010; Urquiza y Aschero 2014). Entre las múltiples interpretaciones de uso (confección de instrumentos como punzones, horquetas de atalaje según Díaz 1995), podrían destacarse las investigaciones llevadas a cabo en las cumbres de los cerros Negro Overo y General 
Belgrano, ambos ubicados en la provincia de La Rioja. Aunque se trate de santuarios de altura (Ceruti 2004, 2007; Martin 2017), en el interior de los recintos se hallaron ofrendas de astas de venado posiblemente empleadas durante ceremonias y probables peregrinajes durante festividades rituales.

La avifauna registrada es escasa, e incluye fragmentos de cáscaras de huevo y de una falange, identificadas como Rhea sp. Su presencia en el Recinto 62, como en otros espacios del sitio (Recinto 1-Kancha II, Kallanka I y Sinchiwasi según tipología Lema et al. 2009, Couso et al. 2010), nos habla de prácticas relacionadas al uso de huevos de aves. Según el análisis de diversas investigaciones, los huevos de Rheidae habrían cumplido un rol para el consumo, elementos contenedores de líquidos, objetos decorativos y simbólicos (e.g. Carden y Martínez 2014; Pastor et al. 2012). Este último aspecto cobraría relevancia para la interpretación del presente conjunto debido a que el suri (Rhea pennata) cumplió un rol importante como ave "anunciadora de la lluvia" entre las comunidades de los valles áridos del Noroeste argentino, evidenciado en la iconografía cerámica como en el hecho de ofrendar restos de huevo en "urnas" funerarias del período Tardío del Noroeste argentino (Gómez Augier y Caria 2009).

Uno de los artefactos recuperados es una base de punta ósea con escotadura. Puntas similares fueron encontradas en otros recintos del sitio, tal es el caso de la "Kancha II" (Complejo 16), donde cuatro de las cinco descriptas, fueron confeccionadas sobre diáfisis de metapodio de artiodáctilo (Couso et al. 2010), y de la plataforma ceremonial ushnu. Estudios realizados en contextos funerarios en el valle de Yocavil denominan a este tipo de instrumentos como puntas "cola de golondrina" (González y Tarragó 2005). Por otro lado, similares preformas de nácar a las que aquí presentamos, fueron reconocidas en el valle de Uspallata, Mendoza (Durán et al. 2018). Las mismas fueron descriptas como cuentas de collar, recuperadas en contextos funerarios. Cabe aclarar, que las cuentas de Uspallata se encuentran perforadas, lo que permitiría pensar que las recuperadas en el Recinto 62 podrían ubicarse en una etapa inicial de la cadena operativa de manufactura de cuentas. Sin embargo, la ausencia de artefactos perforadores y la presencia de cuentas terminadas, indicarían que las preformas podrían haber tenido otro uso.

\section{Consideraciones finales}

Las características arquitectónicas que presentan el Complejo 17 y el Recinto 62 en su interior, son distintivas en relación a otros recintos presentes en el sitio. Las excavaciones y estudios llevados a cabo desde el año 2011, establecieron que el recinto presenta ciertas características que escapan del ámbito del comensalismo doméstico. 
Beber, brindar y comer se configuran como prácticas esenciales en la consolidación de relaciones sociales. Siguiendo a Bray (2012), según con quién (personas involucradas) y en dónde (espacios donde se lleven a cabo) se comparta la comida, sumado a la cantidad y su combinación o prácticas para ser preparada, podemos inferir contextos de uso particular. Pensar la presencia de restos animales identificados en un contexto vinculado a la ritualidad inka conlleva ciertas dificultades al momento de verificar que este tipo de registro no se diferencia mucho de lo identificado en otros de El Shincal. Es por ello que creemos necesario establecer las relaciones contextuales que tienen los materiales arqueofaunísticos con otros elementos de la cultura material.

El análisis zooarqueológico que aquí presentamos del Recinto 62 permitió establecer prácticas de consumo y uso de animales domésticos y silvestres. En perspectiva global, se observa una multiplicidad de animales representados, con una selección intencional de partes esqueletarias. Sobre la base de las frecuencias de MNI obtenidas para las distintas especies que consideramos que fueron incorporadas al registro de manera intencional, las frecuencias de partes esqueletarias y las marcas de procesamiento identificadas, entendemos que existió un ingreso de partes ya seleccionadas. No encontramos evidencias que nos permitan suponer que el desposte pudo haber sido en el interior del recinto. Sin embargo, la presencia del fogón en un sector del recinto sumado a los hallazgos de restos de cerámica tosca utilitaria con hollín, comúnmente utilizada para la cocción de alimentos, no podemos descartar que el interior del recinto se produjeron actividades vinculadas a la cocción y que por tanto, hayan involucrado el empleo de porciones de animales.

Entonces ¿es posible, a partir del registro arqueofaunístico, pensar en un contexto de ritualidad? Esto podemos responderlo a partir de la relación con otros tipos de evidencias. Estas serían la arquitectura y disposición espacial del recinto, la presencia de rasgos destacables como la pasarela de rocas planas o pozos de libación, los tipos y morfologías cerámicas reconocidas (buena calidad y decoración) o la manera en que el recinto fue abandonado a través de lo que parece ser un evento de clausura ritualizado. Pero el tipo de animales presentes y por ende la comida preparada, no parece ser la clave distintiva de una diferencia en relación a un consumo más de tipo doméstico. Más bien es la referencia al dónde y con quién se comparte la comida. Pero es necesaria una aclaración que involucra exclusivamente a los restos de animales. La notable presencia, en términos numéricos, de animales silvestres puede estar marcando aquello que ya ha sido detectado para otros sitios inkas. Por ejemplo, en el sitio San Francisco, la abundante presencia de vicuña se relaciona con la práctica de cacería grupal y con eventos festivos en regiones de altura (Miyano et al. 2017). En el contexto de morteros donde se procesaba y preparaban bebidas y alimentos para las fiestas desarrolladas en El Shincal encontramos el mismo fenómeno en cuanto a la abundancia de fauna silvestre 
(Giovannetti 2015). Dejamos abierta la misma posibilidad de la necesidad de consumo de grandes cantidades de comida haya implicado recurrir a la cacería, cuando no también, la búsqueda de una mayor variedad en el "menú culinario" ofrecido en momentos de comensalismo festivo y ritual.

Por ello, no podemos olvidar la idea de que el mismo consumo de alimentos puede acarrear en sí mismo un componente de sacralidad, sobre todo situándonos desde una perspectiva andina. De hecho cuando se concibe una ofrenda se reconoce que se alimenta a ciertos espíritus poderosos (Sillar 2009). Por ello mismo puede ser que se haga una preparación especial de comidas sin que esto signifique que el tipo de comida sea diferente de la que las mismas personas consuman en otro momento. Por ello en el Recinto 62 los restos de animales consumidos no se destacan especialmente. Finalmente, a partir de la identificación de otros factores vinculados a la ritualidad es que podemos hacer una conexión con modos de consumo y uso de animales en un contexto inkaico. Es la recuperación de la vieja premisa arqueológica de la lectura de los objetos en su contexto holístico la que permite pensar otros modos de la zooarqueología, evitando caer en segmentaciones excesivas que pueden sesgar la interpretación.

La idea de un comensalismo que excede lo cotidiano no puede dejar de enmarcarse dentro de nuestras interpretaciones generales respecto del rol que habría jugado El Shincal de Quimivil dentro de una dinámica regional inkaica. Las evidencias de fiestas y ceremonias están fuertemente sustentadas a partir de otros contextos donde fue posible identificar espacios de producción masiva de comidas y bebidas, sumado a sectores de descarte de objetos de cerámica usados en las mismas. Incluso la evidencia arqueoastronómica nos da indicios de fechas posibles de celebración como los solsticios, equinoccios o cenit del Cusco (Corrado et al. 2017). Las prácticas desarrolladas en el Recinto 62 se articularían en estos otros contextos mayores, aunque seguramente el número de participantes fuera más restringido.

Agradecimientos: El trabajo aquí expuesto fue posible gracias al trabajo conjunto de nuestro equipo de investigación. Por ello debemos agradecer a la Dra. Josefina Spina, al Licenciado Gustavo Corrado y la Licenciada Gregoria Cochero. En la campaña de excavación participaron la Licenciada Lucía Aljanati, la Sra. Clara Ocaña, la Sra. Carla Rossi, el Sr. George Flores y el Sr. Gabriel Fernández. Un agradecimiento especial se lo debemos a la familia Morales por recibirnos con cariño cada vez que vamos a Londres. Por último, le debemos un agradecimiento a la Dra. Laura Marchionni, por sus aportes significativos en la redacción y a los/as evaluadores/as que permitieron mejorar el manuscrito original. 


\section{Bibliografía citada}

Acuto, F. A.

1999 Paisaje y dominación: La constitución del espacio social en el imperio Inka. En Sed Non Satiata: Teoría Social en la Arqueología Latinoamericana Contemporánea, A. Zarankin y F. Acuto (Ed.), pp. 33-75. Ediciones del Tridente, Buenos Aires.

Aguilera, A.

2008 De Embriaguez y Borrachera. El brindis con los dioses en el Mundo Andino. En: I Seminario de Patrimonio Agroindustrial. Paisajes Culturales del Vino, el Pan, el Azúcar y el Café. 13 al 15 de mayo de 2008 - Mendoza, Argentina.

Angiorama, C.

2005 Nuevas evidencias de actividades metalúrgicas preincaicas en la Quebrada de Humahuaca (Jujuy, Argentina). Anales del Museo de América 13: 173-198.

Behrensmeyer, A.

1978 Taphonomic and Ecology Information from Bone Weathering. Paleobiology 4: 150-162.

Binford, L.

1981 Bones: Ancient Men and Modern Myths. Academic Press, New York.

Bray, $\mathrm{T}$.

2012 Ritual commensality between Human and Non-Human Persons: Investigating Native Ontologies in the Late Pre-Columbian Andean World. En Between Feasts and Daily Meals: Towards an Archaeology of Commensal Spaces, S. Pollock (Ed.), pp.: 197-212. eTopoi. Journal of Ancient Studies (special volumen) 2.

Carden, N y G. Martínez

2014 Diseños fragmentados. Circulación social de imágenes sobre huevos de Rheidae en Pampa y Norpatagonia. Boletín del Museo chileno de Arte Precolombino 19(2): 55-75.

Ceruti, C.

2004 Arqueología de alta montaña en La Rioja. Salta: Universidad Católica de Salta.

2007. Nuevos avances en la prospección arqueológica del Famatina. En Actas del XVI Congreso Nacional de Arqueología Argentina, Tomo III, pp. 515-520. Universidad Nacional de Jujuy, San Salvador de Jujuy.

Chauca Francia de Zaldívar, L.

2007 Realidad y perspectiva de la crianza de cuyes en los países andinos. Archivos latinoamericanos de producción animal 15 (1): 223-228. 
Corrado, G; M. Giovannetti; S. Giménez Benítez; M. Loperfido y J. Pino Matos

2017 Las alineaciones astronómicas del Cerro Aterrazado Occidental de El Shincal. Resúmenes de VI Escuela y V Jornadas interamericanas de Astronomía Cultural. Lima, Perú.

Couso, M; R. Moralejo; M. Giovannetti; L. del Papa; M. Páez; J. Gianelli; L. Giambelluca; M. Arnosio y R. Raffino

2010 Análisis de la variabilidad material del Recinto 1 - kancha II: aportes para una comprensión de la política incaica en El Shincal de Quimivil. Arqueología 17: 35-55.

D'Altroy, T.

2002 The Incas. Blackwell Publishers, Oxford.

Díaz, N.

1995 Antecedentes sobre la historia natural de la Taruca (Hippocamelus antisensis d'Orbigny 1834) y su rol en la economía Andina. Chungara 27 (1): 45-55.

Durán, V., P. Novellino, L. Menéndez, A. Gasco, E. Marsh, R. Barberena y C. Frigolé 2018 Barrio Ramos I. Prácticas funerarias en el inicio del Período de dominación Inca del Valle de Uspallata (Mendoza, Argentina). Relaciones de la Sociedad Argentina de Antropología XLIII (1): 55-86.

Farrington, I.

2014 The abandonment process at Tambokancha (Zurite, Cuzco): Inca actions and rituals of site closure. Haucaypata 8: 6-29.

Fernández Jalvo, Y. y P. Andrews

2016 Atlas of Taphonomic Identifications. Springer, Berlín.

Fernández Juárez, G.

1994b El banquete aymara: Aspectos simbólicos de las mesas rituales aymaras. Revista Andina 23: 155-189.

Fiore, D. y F. Borella

2010 Geometrías delicadas. Diseños grabados en cáscaras de huevo de Rheidae recuperados en la costa norte del golfo de San Matías, Río Negro. Intersecciones en Antropología 11: 277-293. 
Giovannetti, M.

2015 Agricultura, regadío y molienda en una capital Inkaica. Los sitios El Shincal y Los Colorados, Noroeste Argentino. BAR S2702, South American Archaeology Series $\mathrm{N}^{\circ}$ 22, (ed. por Andrés D. Izeta). Archaeopress, Oxford.

2018 La espacialidad ritual andina a través de enfoques etnográficos y arqueológicos; confluencias cosmogónicas en la constitución de espacios sagrados entre El Shincal de Quimivil y ceremonias actuales de origen cusqueño. Comechingonia 22 (1): 295-338.

Giovannetti, M.; J. Spina; G. Cochero; G. Corrado, L. Aljanati y M. Valderrama 2012 Nuevos estudios en el sector "Casa del Kuraka" del sitio El Shincal de Quimivil (Depto. Belén, Prov. De Catamarca, Argentina). Revista Inka Llaqta 3: 161-190.

Giovannetti, M. y J. Lynch

2019 Incorporando las wakas antiguas. El Tawantinsuyu en los valles de Hualfín y Quimivil a partir de los espacios sagrados preincaicos. En Memoria del $56^{\circ}$ Congreso Internacional de Americanistas, M. Alcántara y M. García Montero (Edit.), pp. 1107-1117. Universidad de Salamanca, España.

Gómez Augier, J. y M. Caria

2009 La simbología prehispánica e histórica del Noroeste Argentino y su relación con los cambios paleoambientales. Anales del Museo de América XVII: 96-105.

González, L. R. y M. N. Tarragó

2005 Vientos del sur. El valle de Yocavil (Noroeste Argentino) bajo la dominación incaica. Estudios Atacameños 29: 67-95.

Hallowell A.I.

1960 Ojibwa Ontology, Behavior, and World View. En Culture in History: Essays in Honor of Paul Radin (ed. por S. Diamond), pp. 19-52. Columbia University Press, New York.

Hill, E.

2013 Archaeology and animal persons: Toward a prehistory of human-animal relations. Environment y Society 4: 117-136.

Lema, V., M, Giovannetti., C, Deschamps., A, Capparelli y R, Raffino

2009 Análisis de restos faunísticos en el sitio inkaico El Shincal (Catamarca, Argentina). Comparación con información arqueobotánica y análisis cerámico. En La alimentación en la América precolombina y colonial: una aproximación interdisciplinaria (ed. por A. Capparelli, A. Chevalier, y R. Piqué), pp. 97-112. CSIC-CSIC, Madrid. 
Lyman, R.

1994 Vertebrate Taphonomy. Cambridge University Press, Cambridge.

Martin, S.

2017 El Qhapaq Ñam en Famatina (La Rioja-Argentina): ritualidad y manifestaciones sagradas inkas en una Wak'a interregional al sur del kollasuyu. Boletín del Museo chileno de Arte Precolombino 22 (2): 181-198.

Mengoni Goñalons, G.

1988 Análisis de materiales faunísticos de sitios arqueológicos. Xama 1: 71-120.

1999. Cazadores de guanacos de la estepa patagónica. Sociedad Argentina de Antropología, Buenos Aires.

2010. Zooarqueología en la práctica: Algunos temas metodológicos. Xama 19: 83-113.

Miyano, J., I. Lantos, N. Ratto y M. Orgaz

2017 Animales e Incas en el oeste Tinogasteño (Catamarca, Argentina). Latin American Antiquity 28 (1): 28-45.

Murra, J.

1999 La organización económica del Estado Inca (sexta edición). Siglo XXI Editores, México.

Pacheco Torres, V., A. Altamirano Enciso y E. Guerra Porras

1986 The Osteology of South American Camelids. University of California, Los Ángeles.

Palamarczuk, V., R. Spano, F. Weber, D. Magnífico, S. López y M. Manasiewicz

2006 Soria 2. Apuntes sobre un sitio Formativo en el valle de Yocavil (Catamarca, Argentina). Intersecciones en Antropología 8: 121-134.

Pastor, S., M. Medina, A. Recalde, L. López y E. Berberián

2012 Arqueología de la región montañosa central de Argentina. Avances en el conocimiento de la historia Prehispánica Tardía. Relaciones de la Sociedad Argentina de Antropología 37 (1): 89-112.

Pino Matos, J.

2010 Yllapa Usno: rituales de libación, culto a ancestros y la idea del ushnu en los Andes según los documentos coloniales de los siglos XVI-XVII. Arqueología y Sociedad 21: 77-108.

Politis, G., P. Messineo, C. Kaufmann, M. Barros, M. Álvarez, V. Di Prado y R. Scalise 2005 Persistencia ritual entre cazadores-recolectores de la llanura pampeana. Boletín de Arqueología PUCP N9: 67-90. 
Raffino, R.

1981 Los Inkas del Kollasuyu. 2da Ed. Ramos Americana Editora, La Plata.

1999 Las tierras altas del Noroeste. En Nueva Historia de la Nación Argentina. Tomo 1: La Argentina aborigen. Conquista y colonización. Cap. 3, pp: 83-108. Editorial Planeta, Buenos Aires.

2004 Capítulo 1: El Shincal de Quimivil. En: El Shincal de Quimivil (ed. por R. Raffino). pp. 22-43. Sarquís editores, San Fernando del Valle de Catamarca.

Ríos Mencias, J.

2012 Jamut’aq y Kamayuq, Sabios, Científicos y Maestros. Edición Personal, Cusco.

Rodríguez Loredo, C.

1997-1998 Estudio arqueozoológico del sitio inca Potrero-Chaquiago, Barrios La Solana y Retambay, Andalgalá, Pcia. de Catamarca (Argentina). Relaciones de la Sociedad Argentina de Antropología XXII-XXIII: 203-245.

Rostworowski, M.

1999 Historia de Tahuantinsuyu. Instituto de Estudios Peruanos, Lima.

Salemme, M., L. Miotti y E. Tonni

1989 Determination of mammal bones in the zooarchaeological research. En Ind Deya Conference of Prehistory. Volume I: Archaeological Techniques and Technology, W. H. Waldren, J. A. Ensenyat y R. C. Kennard (Edit.), pp. 209-222. BAR International Series 573. London.

Sillar B.

2009 The Social Agency of Things? Animism and Materiality in the Andes. Cambridge Archaeological Journal 19 (3): 367-77.

Shipman, P., G, Foster, y M. Schoeninger

1984 Burnt Bones and Teeth: An Experimental Study of Color, Morphology, Crystal Structure and Shrinkage. Journal of Archaeological Science 2: 307-325.

Tarragó, M.N., L.R. González, G. Ávalos y M. Lamamí

2010 Oro de los señores. La Tumba 11 de la isla de Tilcara (Jujuy, Noroeste Argentino). Boletín del Museo chileno de Arte Precolombino 15 (2): 47-63.

Urquiza, S.V. y P. Babot

2018 Ofrendar y propiciar. Fauna y prácticas agropastoriles prehispánicas del segundo milenio AP en Antofagasta de la Sierra, Puna Meridional Argentina. Archaeofauna, International Journal of Archaeozoology 27: 209-232. 
Urquiza, S.V. y C.A. Aschero

2014 Economía animal a lo largo del Holoceno en la Puna Austral Argentina: Alero Punta de La Peña 4. Cuadernos del Instituto Nacional de Antropología y Pensamiento Latinoamericano 2 (1): 86-112.

Yacobaccio, H.D. y C. Madero

1992 Zooarqueología de Huachichocana III (Jujuy, Argentina). Arqueología 2: 149-188

Ziolkowski, M.

2015 El Calendario metropolitano del Estado Inca. Ediciones El Lector, Lima. 